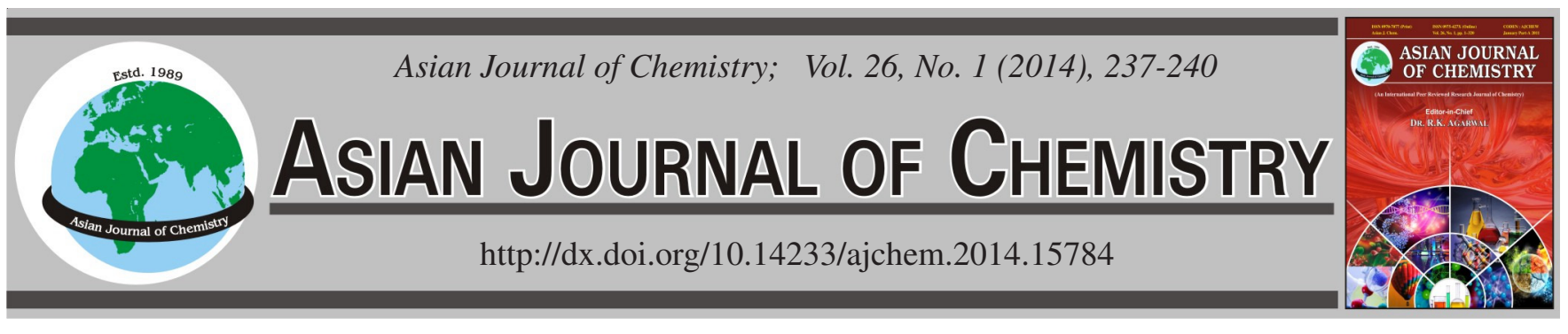

\title{
Synthesis, Supramolecular Structure, Antimicrobial and Plant-Growth Regulation Activities of N-Benzoylthiourea
}

Meng-Meng Zhao, Xiu-Yan Dong ${ }^{*}$, Yu-Hua Yang, Gang Li and Yu-Jie Zhang

School of Chemical and Biological Engineering, Lanzhou Jiaotong University, Lanzhou 730070, P.R. China

*Corresponding author: E-mail: dxy568@163.com

Received: 16 May 2013;

Accepted: 18 July 2013;

Published online: 26 December 2013;

AJC-14513

\begin{abstract}
$\mathrm{N}$-Benzoylthiourea has been synthesized and characterized by elemental analysis, IR and ${ }^{1} \mathrm{H}$ NMR etc. The X-ray crystallography of the compound indicates that the carbonyl group forms an intramolecular hydrogen bond with the N2-H2 group, which forms a six-membered ring $(\mathrm{C} 7 / \mathrm{N} 1 / \mathrm{C} 8 / \mathrm{N} 2 / \mathrm{H} 2 / \mathrm{O} 1)$ srtucture. Each molecule are linked by the intermolecular N2-H2A...S2 and N4-H4A...S1 hydrogen bonds to form a dimer, adjacent dimers are linked by the intermolecular N1-H1N...S2 and N3-H3N...S1 hydrogen bonds, leading to a hydrogenbonded netty structure. The results indicated that the N-benzoylthiourea played the important role in plant-growth regulators and may be a potential source of active antimicrobial agents.
\end{abstract}

Keywords: Thiourea, Synthesis, Crystal structure, Antibacterial, Plant-growth regulation activity.

\section{INTRODUCTION}

Thiourea and its derivatives, especially acylthiourea, are extensively studied because of their biological activities such as herbicides, insecticides, plant-growth regulators, antifungal, antibacterial and pharmacodynamics ${ }^{1-5}$. Some thioureas are organic reaction catalyst in the metal-catalyzed asymmetric reduction of carbonyl compounds and carbonylative cyclization of $o$-hydroxyarylacetylenes ${ }^{6,7}$. With the rapid development of supramolecular chemistry, thioureas are one of many important neutral receptors because of their anion recognition properties ${ }^{8-10}$, $\mathrm{H}$-atom of thiourea group $\mathrm{N}-\mathrm{H}$ bond form easily hydrogen bond, which recognize the anion by the interaction of the hydrogen bond and the anion. In a ${ }^{13} \mathrm{C}$ NMR study, the differences between the benzoyl $(\mathrm{CO})$ chemical shift value of $\mathrm{N}$-monosubstituted and $\mathrm{N}, \mathrm{N}$-disubstituted indicated the existence of an intramolecular hydrogen bond, namely between the benzoyl (CO) and the $\mathrm{N}-\mathrm{H}$ group. The indication was also supported by the ${ }^{1} \mathrm{H}$ NMR spectrum ${ }^{11}$. Here we report synthesis and crystal structure of N-benzoylthiourea, $\mathrm{C}_{8} \mathrm{H}_{8} \mathrm{~N}_{2} \mathrm{OS}$. Then tested it possessed prominent antimicrobial and plant growth regulation activities.

\section{EXPERIMENTAL}

All chemicals were of analytical reagent grade and were used without further purification. $\mathrm{C}, \mathrm{H}$ and $\mathrm{N}$ analyses were obtained using a GmbH VarioEL V3.00 automatic elemental analysis instrument. The IR spectrum in the range of 4000-
$400 \mathrm{~cm}^{-1}$ was recorded with a VERTEX70 FT-IR spectrophotometer using $\mathrm{KBr}$ pellets. ${ }^{1} \mathrm{H}$ NMR spectrum was determined by German Bruker AVANCE DRX-400 spectrometers with TMS as internal standard and $\mathrm{d}_{6}-\mathrm{DMSO}$ as solvent. X-ray single crystal structure determination was obtained on a Rigaku RAXIS-RAPID detector. Melting points were obtained by use of a X4 microscopic melting point apparatus made in Beijing Taike instrument limited company and were uncorrected.

The antimicrobial activities were determined using agar disc diffusion method by measuring the inhibition zone in $\mathrm{mm}$. All organisms were obtained from the China Center of Industrial Culture Collection, including 2 bacterial stains: Escherichia coli ACCC11864 as gram-negative bacteria, Bacillus subtilis ACCC 01518 as gram-positive bacteria, 4 fungal stains: Botrytis cinerea ACCC35153, Thanatephorus cucumeris ACCC30367, Phyricularia grisea ACCC100762 and Fusarium oxysporum ACCC13422. Ampicillin and fluconazole were served as standard antibacterial and antifungal agents, respectively. The plant growth regulation activities were determined using in vitro plate method. The seeds of rape were brought from Seed store.

\section{General procedure}

Synthesis of N-benzoylthiourea: Benzoyl chloride (1.41 $\mathrm{g}, 10 \mathrm{mmol})$ was reacted with ammonium thiocyanate $(1.14$ $\mathrm{g}, 15 \mathrm{mmol})$ in $\mathrm{CH}_{2} \mathrm{Cl}_{2}(25 \mathrm{ml})$ solution under soild-liquid phase transfer catalysis, using polyethylene glycol-400 (0.18 $\mathrm{g}$ ) as the catalyst, to give the corresponding benzoyl isothiocyanate. 


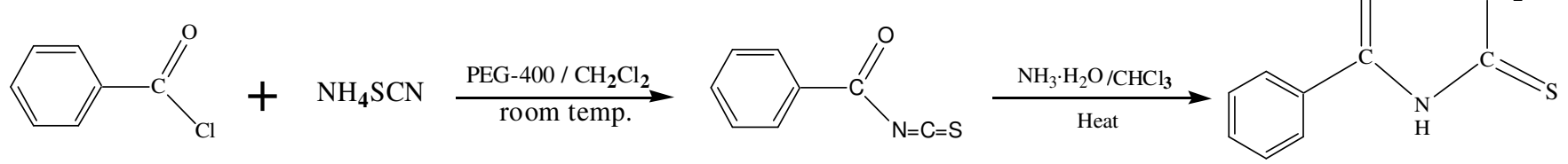

Scheme-I: Synthetic scheme of the title compound.

The resulting mixture was evaporated to dryness using a rotatory evaporator and the residue was extracted with chloroform, to give the title compound. Yield 84.6\%. m.p. 386-388 K. Anal. Calcd. (\%) for $\mathrm{C}_{8} \mathrm{H}_{8} \mathrm{~N}_{2} \mathrm{OS}$ : C, 53.31; $\mathrm{H}, 4.47 ; \mathrm{N}, 15.54$. Found (\%): C, 53.23; H, 4.58; N, 15.32. Selected IR data $\left(\mathrm{cm}^{-1}, \mathrm{KBr}\right.$ pellet $): 3310,3225\left(v_{\mathrm{NH}}\right), 1680\left(\mathrm{v}_{\mathrm{C}=\mathrm{O}}\right)$ and $1031\left(\mathrm{v}_{\mathrm{C}=\mathrm{S}}\right) .{ }^{1} \mathrm{H} \mathrm{NMR}$ (400 MHz, $\left.\mathrm{CDCl}_{3}, \delta, \mathrm{ppm}\right)$ : 7.53-7.87 (m, 5H,Ar-H), 9.98 (s, $1 \mathrm{H}, \mathrm{HN}), 10.06(\mathrm{~s}, 2 \mathrm{H}, \mathrm{H} 2 \mathrm{~N})$.

Colorless needle-shaped single crystals were obtained by slow evaporation of an chloroform solution after several weeks at room temperature. Synthetic scheme of the title compound was shown in Scheme-I.

X-ray structure determination: The colorless crystal with a dimension of $0.67 \mathrm{~mm} \times 0.48 \mathrm{~mm} \times 0.13 \mathrm{~mm}$ was placed on a Rigaku RAXIS-RAPID detector. Intensity data were collected with a graphite-monochromator MoK $\alpha$ radiation $(\lambda=0.71073 \AA)$ at $153(2) \mathrm{K}$. The structure was solved by direct methods and refined by full matrix least squares on $\mathrm{F}^{2}$

TABLE-1

CRYSTAL DATA AND STRUCTURE REFINEMENT FOR THE TITLE COMPOUND

\begin{tabular}{ll}
\hline Empirical formula & $\mathrm{C}_{8} \mathrm{H}_{8} \mathrm{~N}_{2} \mathrm{OS}$ \\
Formula weight & 180.22 \\
Temperature $(\mathrm{K})$ & $153(2)$ \\
Wavelength $(\AA)$ & 0.71073 \\
Crystal system & Triclinic \\
Space group & $\mathrm{P}-1$ \\
Cell dimensions, $(\AA, \mathrm{deg})$ & $\mathrm{a}=8.1862(4), \mathrm{b}=9.2399(5)$, \\
& $\mathrm{c}=12.4921(8), \alpha=73.509(2)$, \\
& $\beta=87.766(2), \gamma=70.556(2)$ \\
Volume $\left(\AA^{3}\right)$ & $852.74(8)$ \\
$\mathrm{Z}$ & 4 \\
Density (calculated) $\left(\mathrm{mg} / \mathrm{m}^{3}\right)$ & 1.404 \\
Absorption coefficient $\left(\mathrm{mm}^{-1}\right)$ & 0.329 \\
$\mathrm{~F}_{\text {(000) }}$ & 376 \\
Index ranges & $-10 \leq \mathrm{h} \leq 10,-11 \leq \mathrm{k} \leq 11,-16$ \\
& $\leq 1 \leq 16$ \\
Reflections collected & $8370 / 3864[\mathrm{R}(\mathrm{int})=0.0205]$ \\
Independent reflections & 3566 \\
Data/restraints/parameters & $3864 / 0 / 242$ \\
Goodness of fit indicator & 0.996 \\
$\mathrm{R}[\mathrm{I}>2 \sigma(\mathrm{I})]$ & $\mathrm{R}_{1}=0.0289, \mathrm{wR}=0.0850$ \\
Largest diff. peak and hole $\left(\mathrm{e} \AA^{-3}\right)$ & 0.359 and -0.277 \\
\hline
\end{tabular}

using the program. All hydrogen atoms were added theoretically. The final refinements converged at $\mathrm{R}_{1}=0.0289, \mathrm{wR}_{2}=0.0850$ with $\omega=1 /\left[\sigma^{2}\left(\mathrm{~F}_{\mathrm{o}}^{2}\right)+(0.0526 \mathrm{P})^{2}+0.2490 \mathrm{P}\right]$, where $\mathrm{P}=\left(\mathrm{F}_{\mathrm{o}}^{2}+\right.$ $\left.2 \mathrm{~F}_{\mathrm{c}}^{2}\right) / 3$. All atoms were refined with anisotropic displacement parameters. The largest differential peak and hole were 0.359 and $-0.277 \mathrm{e}^{-3}$. The structural plots were drawn with SHELXL 97 software package ${ }^{12}$. The crystal data and experimental parameters relevant to the structure determination are listed in Table-1.

Antimicrobial activity: The culture media used were nutrient agar and Sabourd's medium for bacteria and fungus strains, respectively. The hot nutrient agar and sabourd's medium solution was poured into sterilized petridishes and allowed to attain room temperature. Seed layer medium which contains the previously grown subculture was lawned into the Petri dishes. Cups were made using sterile borer of $5 \mathrm{~mm}$ diameter. To these cups $0.5 \mathrm{~mL}$ of the drug solution $(50 \mu \mathrm{g} / \mathrm{mL})$, standard solution were added and allowed to cool for $1 \mathrm{~h}$ to facilitate diffusion. The plate was incubated at $37^{\circ} \mathrm{C}$ or $28^{\circ} \mathrm{C}$ for $48 \mathrm{~h}$. Zone of inhibition around wells were measured. All tests were repeated three times to confirm the results. The results are presented in Table-2.

Plant-growth regulators determination: The method of vitro plate was adopted. Twain's 80 was used as emulsifier, the compound was dissolved in the solution of N,N-dimethylformamide. Six kinds of solution were configurated with distilled water respectively $(100,10,01.0,0.1,0.01,0.001$ $\left.\mathrm{mg} \mathrm{L}^{-1}\right)$. Put $10 \mathrm{~mL}$ solution with differents concentration into $9 \mathrm{~mm}$ culture plate (including 2 layers of filter paper), use equivalent emulsifier as contrast. 15-20 healthy seeds of Brassica napus were choosen and puted into every plate, The plates were incubated at $25 \pm 5^{\circ} \mathrm{C}$ for $72 \mathrm{~h}$. Then for day light $8 \mathrm{~h}$ every day, examined after $5 \mathrm{~d}$. Measured the growth of the root and the stem, calculated the percentage of plant growth regulator activity.

The promotion rate (the inhibition rate) $=\left(\mathrm{N}-\mathrm{N}_{1}\right) / \mathrm{N}_{1} \times$ $100 \%$. $\mathrm{N}_{1}$ : The average of the length of rape root in distill water, $\mathrm{N}$ : The average of the length of rape root in compound solution All tests were repeated three times to confirm the results. The results are presented in Table-3.

TABLE-2

RESULTS OF ANTITUBERCULOSIS AND ANTIMICROBIAL ACTIVITIES FOR THE TITLE COMPOUND

\begin{tabular}{|c|c|c|c|c|c|c|}
\hline \multirow{2}{*}{ Compound } & \multicolumn{6}{|c|}{ Diameter of zone of inhibition (mm) } \\
\hline & B. subtilis & E. coli & B. cinerea & T. cucumeris & P. grisea & F. oxysporum \\
\hline N-Benzoylthiourea & $8.9 \pm 0.25$ & - & $11.4 \pm 0.35$ & $12.9 \pm 0.2$ & $10.4 \pm 0.35$ & $7.8 \pm 0.15$ \\
\hline Ampicillin & $10.3 \pm 0.3$ & $12.6 \pm 0.5$ & & - & - & - \\
\hline Fluconazole & - & - & $13.2 \pm 0.6$ & $14.9 \pm 0.55$ & $15.4 \pm 0.6$ & $14.2 \pm 0.65$ \\
\hline
\end{tabular}




\begin{tabular}{ccc}
\hline \multicolumn{3}{c}{ TABLE-3 } \\
\multicolumn{3}{c}{$\begin{array}{c}\text { DATA OF PLANT GROWTH REGULATION ACTIVITY OF } \\
\text { TARGET FOR THE TITLE COMPOUND }\end{array}$} \\
\hline $\mathrm{C}\left(\mathrm{mg} \mathrm{L}^{-1}\right)$ & Indolylacetic acid & N-Benzoylthiourea \\
\hline 0.001 & $4.5 \pm 0.1$ & $-19.8 \pm 0.11$ \\
0.01 & $6.9 \pm 0.12$ & $-22.0 \pm 0.24$ \\
0.1 & $-12.5 \pm 0.23$ & $-39.3 \pm 0.6$ \\
1.0 & $-62.1 \pm 0.3$ & $-11.7 \pm 0.25$ \\
10 & $-85.9 \pm 1.2$ & $-37.5 \pm 0.4$ \\
100 & $-98.1 \pm 3.1$ & $-73.6 \pm 0.31$ \\
\hline
\end{tabular}

\section{RESULTS AND DISCUSSION}

Description of crystal structure: Selected bond lengths and angles are listed in Table-4. The data for hydrogen bonds are given in Table-5. The molecular structure with atom label1ing, two-dimensional mono-layer structure and its packing diagram along $c$-axis were shown in Figs. 1-3, respectively.

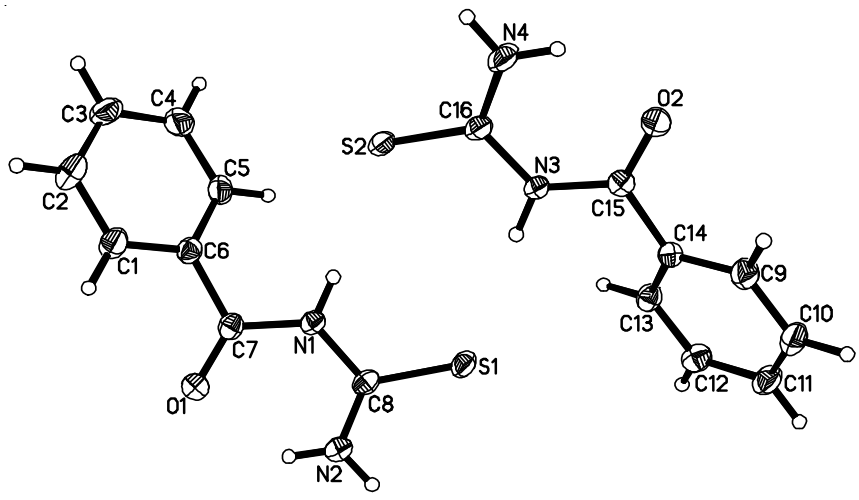

Fig. 1. Crystal structure and atom numbering of the title compound

The crystal structure of the title compound is built up by only the $\mathrm{C}_{8} \mathrm{H}_{8} \mathrm{~N}_{2} \mathrm{OS}$ molecules. X-ray crystallographic analysis revealed the crystal structure of $\mathrm{N}$-benzoylthiourea, which the carbonyl group forms an intramolecular hydrogen bond with

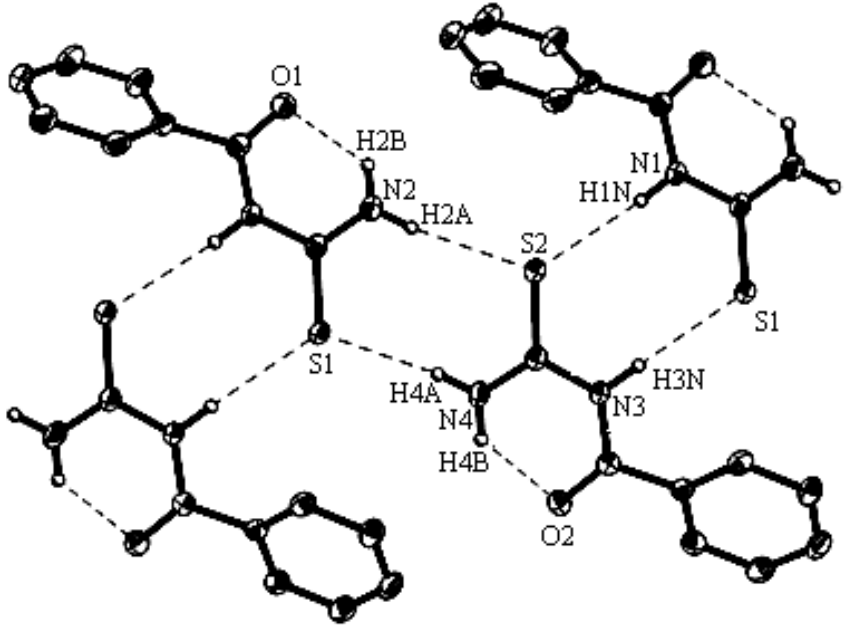

Fig. 2. The two-dimensional mono-layer netty structure. Hydrogen bonds are illustrated by dashed line

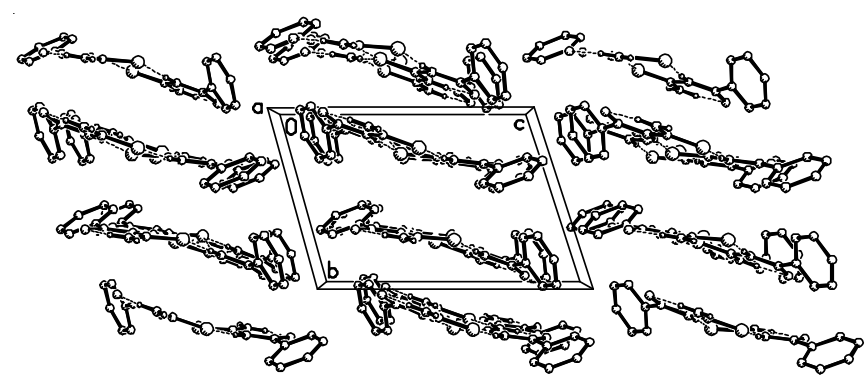

Fig. 3. Three-dimensional packing diagram of the title compound, $\mathrm{H}$ atoms are omitted for clarity

the N2-H2 group, which forms a six-membered ring (C7/N1/ $\mathrm{C} 8 / \mathrm{N} 2 / \mathrm{H} 2 / \mathrm{O} 1)$ srtucture. This is similar to that found in N-benzoyl-N'-(3-pyridyl)thiourea ${ }^{13,14}$. The $\mathrm{C}=\mathrm{O}$ bond length is $1.22(3) \AA$, longer than the normal $\mathrm{C}=\mathrm{O}$ bond length $(1.20$ (3) $\AA$ ), which is due to intramolecular hydrogen bond. The bond

\begin{tabular}{|c|c|c|c|c|c|}
\hline \multicolumn{6}{|c|}{$\begin{array}{c}\text { TABLE-4 } \\
\text { SELECTED BOND DISTANCES }(\AA) \text { AND ANGLES }\left(^{\circ}\right) \text { FOR THE TITLE COMPOUND }\end{array}$} \\
\hline Bond & Lengths & Bond & Lengths & Bond & Lengths \\
\hline S1-C8 & $1.685(1)$ & $\mathrm{N} 2-\mathrm{C} 8$ & $1.314(2)$ & $\mathrm{C} 3-\mathrm{C} 4$ & $1.384(2)$ \\
\hline O1-C7 & $1.220(1)$ & $\mathrm{C} 1-\mathrm{C} 2$ & $1.385(2)$ & C4-C5 & $1.392(2)$ \\
\hline N1-C8 & $1.382(1)$ & C1-C6 & $1.392(2)$ & C5-C6 & $1.391(2)$ \\
\hline N1-C7 & $1.384(1)$ & $\mathrm{C} 2-\mathrm{C} 3$ & $1.385(2)$ & C6-C7 & $1.491(2)$ \\
\hline Bond & Angles & Bond & Angles & Bond & Angles \\
\hline C8-N1-C7 & $126.9(1)$ & C6-C5-C4 & $119.6(1)$ & O1-C7-C6 & $122.2(1)$ \\
\hline $\mathrm{C} 2-\mathrm{C} 1-\mathrm{C} 6$ & $120.12(1)$ & C5-C6-C1 & $119.9(1)$ & N1-C7-C6 & $114.7(1)$ \\
\hline $\mathrm{C} 1-\mathrm{C} 2-\mathrm{C} 3$ & $119.9(1)$ & C5-C6-C7 & $121.9(1)$ & N2-C8-N1 & $118.3(1)$ \\
\hline $\mathrm{C} 4-\mathrm{C} 3-\mathrm{C} 2$ & $120.2(1)$ & C1-C6-C7 & 18.1(1) & N2-C8-S1 & $123.45(9)$ \\
\hline C3-C4-C5 & $120.2(1)$ & O1-C7-N1 & $123.0(1)$ & N1-C8-S1 & $118.25(8)$ \\
\hline
\end{tabular}

TABLE-5

DATA FOR HYDROGEN-BONDING INTERACTIONS $\left(\AA,^{\circ}\right)$

\begin{tabular}{|c|c|c|c|c|c|}
\hline D-H $\cdots A$ & $\mathrm{~d}(\mathrm{D}-\mathrm{H})$ & $\mathrm{d}(\mathrm{H} \cdots \mathrm{A})$ & $d(D \cdots A)$ & $\angle \mathrm{D}-\mathrm{H} \cdots \mathrm{A}$ & Symmetry code \\
\hline N1-H1N...S2 & 0.89 & 2.47 & $3.353(1)$ & 176 & $\mathrm{x}, \mathrm{y}, \mathrm{z}$ \\
\hline N3-H3N...S1 & 0.91 & 2.50 & $3.401(1)$ & 174 & $\mathrm{x}, \mathrm{y}, \mathrm{z}$ \\
\hline N2-H2B...O1 & 0.86 & 2.03 & $2.664(2)$ & 131 & $\mathrm{x}, \mathrm{y}, \mathrm{z}$ \\
\hline N2-H2A...S2 & 0.87 & 2.61 & $3.447(1)$ & 164 & $1+x, y, z$ \\
\hline N4-H4B...O2 & 0.87 & 1.95 & $2.621(2)$ & 132 & $\mathrm{x}, \mathrm{y}, \mathrm{z}$ \\
\hline N4-H4A...S1 & 0.88 & 2.41 & $3.282(2)$ & 173 & $-1+x, y, z$ \\
\hline
\end{tabular}


lengths of intramolecular hydrogen bonds $\mathrm{H} 2 \mathrm{~B} . . . \mathrm{O} 1$ and H4B...O2 are 2.02(2) and 1.95(2) $\AA$ and the bond lengths of intermolecular hydrogen bonds H1N...S2, H3N...S1, H2A...S2, H4A...S1 are 2.47(2), 2.50(2), 3.56(2) and 2.41(2) A, respectively. Fig. 2 is shown that four distinct hydrogen bonds occur in the crystal structure: which each pair molecules are linked by the intermolecular N2-H2A...S2 (-x+1, -y, -z+1), N4H4A...S1 ( $\mathrm{x}-1, \mathrm{y}, \mathrm{z})$, hydrogen bonds to form a dimer, adjacent dimers are linked by the intermolecular N1-H1N...S2, N3-H3N...S1 hydrogen bonds, leading to a hydrogen-bonded netty structure s-17. $^{15}$.

Antimicrobial and plant-growth regulation activities: $\mathrm{N}$-Benzyl thiourea has shown good antimicrobial activities as compared to their standard drugs but the antifungal activities are more prominent. Especially in plant pathogens, it reveals extraordinary disinfect abilities in cucumber gray mold, rice sheath blight disease, Rice blast and Fusarium Wilt of cotton. It also played the role of plant-growth regulators, at the concentration of $0.1 \mathrm{mg} / \mathrm{L}, 10 \mathrm{mg} / \mathrm{L}$ and $100 \mathrm{mg} / \mathrm{L}$, it has prominent plant growth regulation activties. These results indicated the potential of the N-benzyl thiourea as antimicrobial and plantgrowth regulators, in these aspects the research of the $\mathrm{N}$-benzoylthiourea is suggested for further work.

\section{REFERENCES}

1. A. Jurasek, P. Saferr and V. Zvak, Chem. Pap., 41, 693 (1987)

2. S.G. Teoh, S.H. Ang, H.K. Fun and C.-W. Ong, J. Organomet. Chem., 580, 17 (1999).
3. U. Bierbach, T.W. Hambley, J.D. Roberts and N. Farrell, Inorg. Chem. 35, 4865 (1996).

4. R. del Campo, J.J. Criado, E. García, M.R. Hermosa, A. JiménezSánchez, J.L. Manzano, E. Monte, E. Rodríguez-Fernández and F. Sanz, J. Inorg. Biochem. 89, 74 (2002).

5. J. Huang, J.R. Song and Y.H. Ren, Chinese, J. Struct. Chem., 25, 168 (2006).

6. Y. Nan, H. Miao and Z. Yang, Org. Lett., 2, 297 (2000).

7. J.A.J. Breuzard, M.L. Tommasino, F. Touchard, M. Lemaire and M.C. Bonnet, J. Mol. Catal. A: Chem., 156, 223 (2000).

8. P. Buhlmann, S. Nishizawa, K.P. Xiao and Y. Umezawa, Tetrahedon, 53, 1647 (1997).

9. Y.M. Zhang, W.X. Xu, Y.Q. Zhou, H. Yao and T.-B. Wei, Acta Chim. Sinica, 64, 79 (2006).

10. J. Valdés-Martínez, S. Hernández-Ortega, M. Rubio, D.T. Li, J.K. Swearingen, W. Kaminsky, D.R. Kelman and D.X. West, J. Chem. Crystallogr., 34, 533 (2004).

11. K.R. Koch, C. Sacht and S. Bourne, Inorg. Chim. Acta, 232, 109 (1995).

12. G.M. Sheldrick, SHELXL-97. Program for the Refinement of Crystal Structures. University of Göttingen, Germany 1997.

13. W.K. Dong, X.Q. Yang and J.H. Feng, Acta Crystallogr. E62, o3459 (2006).

14. W.K. Dong, X.Q. Yang, L.-Q. Chai, Y.-Q. Tian and J.-H. Feng, Phosphorus, Sulfur Silicon Rel. Elem., 183, 1181 (2008).

15. W.K. Dong, Y.X. Sun, Y.P. Zhang, L. Li, X.N. He and X.L. Tang, Inorg. Chim. Acta, 362, 117 (2009).

16. W.K. Dong, X.N. He, H.B. Yan, Z.W. Lv, X. Chen, C.Y. Zhao and X.L. Tang, Polyhedron, 28, 1419 (2009).

17. W.K. Dong, Y.X. Sun, Y.P. Zhang, L. Li, X.N. He and X.L. Tang, Inorg. Chim. Acta, 362, 117 (2009). 